\title{
Identidade e Bilnguismo em ConteXto de Núcleo Familiar de Imigrantes ItaLianos
}

\author{
Fernanda Ortale* \\ Giliola Maggio \\ PAOLA BaCGiN
}

RESUMO: O objetivo deste artigo é refletir sobre questões de identidade e bilinguismo em um núcleo familiar de imigrantes italianos. Os dados coletados consistem em uma entrevista realizada com um casal de italianos radicados no Brasil desde 1957. Iniciamos o artigo com um breve quadro da imigração italiana no Brasil, em seguida, analisamos o processo de construção de identidades que emergem durante as narrativas, bem como o bilinguismo que se delineia nesse contexto.

PALAVRAS-CHAVE: identidades; bilinguismo; narrativas.

ABSTRACT: Lo scopo di questo testo è riflettere su identità e bilinguismo in un nucleo familiare di immigrati italiani. I dati raccolti consistono in un'intervista realizzata a una coppia di italiani arrivati in Brasile nel 1957. All'inizio presentiamo un panorama dell'immigrazione italiana in Brasile, poi analizziamo non solo la costruzione delle identità che emergono dalle storie ma anche il bilinguismo delineato in questo contesto.

PAROLE CHIAVE: identità; bilinguismo; storie di vita.

ABSTRACT: The aim of this article is to reflect on identity and bilingualism in

*As três autoras são docentes da Área de Língua e Literatura Italiana e do Programa de Pós-Graduação em Língua, Literatura e Cultura Italianas da Universidade de São Paulo. 
a family of Italian immigrants. The collected data consist of an interview with an Italian couple living in Brazil since 1957. We started the article with a brief profile of Italian immigration in Brazil, and then we analyzed the identity building process which emerges in the narratives and how bilingualism is outlined in this context. KEYWORDS: identity; bilingualism; narratives. 


\section{Introdução}

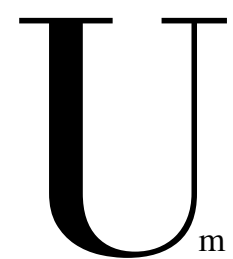

m estudo da literatura sobre imigração italiana no Brasil permite afirmar que há uma concentração de pesquisas referentes aos momentos da imigração massiva, de 1870 a 1902 . A maior parte dos estudos focaliza até o término da Segunda Grande Guerra ${ }^{1}$, como os trabalhos de Hall, M. (1979, 2004); Trento (1984, 1989); Barreto (1994); Gabriel (1995), Bertonha (1998), Facchinetti (2003), entre outros. Tal fato deve-se, provavelmente, ao expressivo número de imigrantes italianos vindos ao Brasil no referido período. Dados estatísticos registram a chegada de 1.208.042 italianos no decorrer de trinta e sete anos, no período de 1870 a $1907^{2}$. Para ter uma ideia da expressividade deste número em relação aos anos sucessivos, os dados registram a chegada de 357.793 italianos de 1908 a 1953; ou seja, no período dos quarenta e cinco anos

1 Di Gianni (1997) aponta a falta de pesquisas sobre imigração italiana relativa ao período posterior à II Guerra e anterior ao adensamento do fluxo migratório para o Brasil.

2 Dados estatísticos registrados pelo Memorial do Imigrante (www.memorialdoimigrante.sp.gov.br). 
seguintes o número de imigrantes corresponde a cerca de um quarto em relação ao número de imigrantes que chegaram no período dos trinta e sete anos anteriores a 1908.

Hall, M. (1979, p. 202) atribui o fenômeno de imigração italiana de massa (1870-1902) a uma coincidência histórica entre os dois países. De um lado, a Itália, que atravessava os anos mais críticos de sua economia e, de outro, o Brasil, que atravessava a crise de mão de obra.

As dificuldades que enfrentaram os imigrantes italianos no Brasil são relatadas em diversos materiais de pesquisa que tiveram como base a tradição de narrativas orais, bem como documentos da época.

Os registros da entrevista realizada com o casal de imigrantes italianos, que servem de base para refletir sobre o tema da identidade, foram gravados em áudio de uma hora e quarenta minutos. Visto que o foco do trabalho não é analisar a variedade linguística utilizada pelos entrevistados, foram realizadas, durante a transcrição, adaptações da fala oral (em português) para a escrita, anulando características da fala, como, por exemplo, a ausência da pronúncia da consoante " $r$ " final e desvios de concordância verbal e nominal segundo a norma culta.

\section{Bilinguismo e construção de identidades}

Um dia, meu irmão ficou doente, eu estava com o meu pai, e eu fiz dez sacas de café. Sabe o que é isso? Peneirar 10 sacos de 60 quilos, um moleque de dez anos? Não era fácil, né? Já carpi café, eu já fiz de tudo aqui no país. (Giuseppe)

Uma vez levaram eles pra dormir num paiol lá na fazenda. Só tinha rato. Meu Deus! Um tio dele nem dormiu, sentou do lado da mulher e das duas filhas que ele tinha e ficou tocando os ratos. [...] E diz que as mulheres só choravam, viu? (Giovanna)

Esses relatos são de italianos que chegaram ao Brasil numa época em que a imigração italiana não apresentava mais números tão expressivos quanto os do final do século XIX e início do século XX.

As falas acima são parte de uma entrevista com um casal de italianos, Giovanna e Giuseppe ${ }^{3}$,

3 Devido ao consentimento obtido por parte dos entrevistados, utilizamos os seus verdadeiros nomes. 
provenientes de Gildone, localizado na região de Molise, província de Campobasso, sul da Itália. Em meados dos anos 1950, quando imigraram, partiram juntas nove famílias da mesma cidade, o equivalente a 58 pessoas. À época, a cidade contava com aproximadamente 3.000 habitantes e hoje conta apenas com a metade, cerca de 1.500 habitantes $^{4}$. Há 48 anos no Brasil, a família mantém, ainda, hábitos alimentares italianos, um certo reconhecimento de identidade italiana, e também a língua, ou melhor, o dialeto italiano de Campobasso.

Giovanna e Giuseppe chegaram ao Brasil aos nove anos - portanto, falavam apenas o dialeto de Campobasso que aprenderam com os pais - e aprenderam português no Brasil, sendo, assim, bilíngues. Constata-se um tipo de bilinguismo marcado pela presença do dialeto de Campobasso, que permanece restrito ao âmbito familiar (pais, filhos e irmãos), e do português, que é a língua utilizada no trabalho, nos contatos diários fora do âmbito familiar e com amigos brasileiros. ${ }^{5}$

A variedade de português falada por ambos apresentou-se, durante a entrevista, marcada por empréstimos linguísticos ${ }^{6}$, tais como entonação e uso de palavras em italiano (mais frequentes na fala de Giuseppe). Tanto a aprendizagem do português quanto do dialeto deu-se através do contato oral com a língua, visto que o tempo de frequência à escola brasileira foi muito curto. Giuseppe frequentou por três anos a escola na Itália e por menos de um mês a escola no Brasil, e Giovanna frequentou os três primeiros anos escolares no Brasil. Ambos justificam o abandono escolar da mesma maneira, por problemas de compreensão da língua portuguesa na escola brasileira ${ }^{7}$ :

— Mas lá na fazenda tinha escola? (entrevistadora)

- "Macché"8 escola! Eu entrei na escola eu não entendia nada. Eu não tenho escola, pra te ser sincero eu tenho o terceiro ano na escola: "primo, secondo e terzo".

- E depois, chegando aqui?

— Nada, eu não tive escola nenhuma.

\footnotetext{
4 Esses números foram apontados pelo próprio casal. A grande redução do número de habitantes das cidades do Sul da Itália é um fenômeno comum, devido à migração de jovens que vão ao Norte em busca de oportunidades de emprego. 5 Temos, portanto, uma situação diglóssica. De acordo com Saville-Troike (1989, p. 54), o termo diglossia refere-se a uma situação em que duas ou mais línguas (ou variedades da mesma língua) em uma comunidade de fala são distribuídas entre diferentes funções e contextos sociais. Sobre bilinguismo, veja-se também Skutnabb-Kangas (1981). 6 Segundo Trudgill (1992), empréstimo linguístico é o processo que leva os falantes bilíngues a introduzir palavras de uma língua em outra, e essas palavras tornam-se, eventualmente, aceitas como parte integral da segunda língua. 7 Sobre o tema da escolarização em contextos de minorias linguísticas, sugerimos a leitura de Cavalcanti, 1999. 8 Utilizamos aspas nos momentos em que os entrevistados usam palavras em italiano e a tradução entre colchetes quando se faz necessária.
} 
— Mas tinha escola lá no Paraná?

- Tinha, mas eu não entendia, ia na escola burro e voltava mais burro em casa. Eu não entendia o "parlare", né? [...] Conversava, conversava e eu não entendia nada, aí eu não fui mais, eu comecei a trabalhar. (Giuseppe)

Você muda de país, você ia na escola e não sabia nem falar "bom dia", então, como você vai numa escola se você fica olhando o professor e não entende nada?

Eu fiz até a o terceiro ano. Depois eu fiquei grande, porque nisso já os anos foram passando, aí eu tinha vergonha de ir, porque os outras eram pequenininhas e eu já era uma moçona, né? Já não queria mais ir. (Giovanna)

O mesmo problema que encontraram nas escolas era também encontrado no contato com a sociedade local, pois o desconhecimento da língua portuguesa criou, pelo menos durante a vida na fazenda, um processo de marginalização, em que os imigrantes foram impedidos de participar do grupo que falava a língua que desejavam e precisavam adquirir. Diferentemente do que ocorreu com italianos que imigraram em fazendas na época em que havia muitas colônias italianas, onde era possível haver algum tipo de inserção, ao menos nas comunidades de seus compatriotas; os italianos que vieram em uma época da imigração em baixa escala permaneciam, e permanecem ainda hoje, relativamente isolados em seus pequenos núcleos familiares. Vale observar que, mesmo no caso das colônias italianas, é perfeitamente possível que houvesse grande dificuldade de comunicação, pois a Itália possui ainda hoje inúmeros dialetos diferentes, muitas vezes incompreensíveis entre si.

Nesse sentido, vale lembrar a peculiaridade linguística da cidade de Pedrinhas Paulista, antiga Colônia, fundada em 1952 por imigrantes italianos provenientes de diversas regiões da Itália. Tais imigrantes tiveram contato no local com funcionários da Companhia de Colonização, com brasileiros, e com outros italianos que foram chegando na medida em que a colônia se expandia. Como já comprovado em Castro (2002), no local formou-se uma variedade pedrinhense, resultado do contato entre os diversos dialetos, a língua italiana e o português, facilitando assim a comunicação entre os italianos. De todo modo, em família foram mantidos os respectivos dialetos. Tendo ciência da diversidade linguística italiana, Hall, M. (1979, p. 208) aponta que 
alguns fazendeiros contratavam intencionalmente colonos provenientes de diferentes regiões da Itália, a fim de que seus dialetos e costumes distintos dificultassem a cooperação entre eles.

Apesar do longo período em que estão radicados no Brasil (46 anos) e das sucessivas migrações - do Paraná para Rio Claro e depois para Campinas -, tanto Giovanna quanto Giuseppe mantiveram o uso do dialeto com os pais e irmãos:

- Mas, vocês continuaram falando dialeto?

- Opa! Até hoje! Quando a gente conversa [os dois], a gente fala o dialeto da Itália. (Giovanna)

— É que meu pai, "fa due anni che è morto", em "novembre". O dialeto è "lo stesso" [o mesmo], mas de "cinquant'anni”. (Giuseppe)

— Os irmãos falam dialeto?

- Opa! O dialeto fala a família inteira!

Podemos notar que na fala de Giuseppe ocorrem mudanças de código ${ }^{9}$, pois insere várias palavras italianas para responder à pergunta. Se considerarmos que a pergunta era, justamente, se ele falava ainda o dialeto, sua resposta, com muitas marcas lexicais italianas, pode ser interpretada como uma estratégia comunicativa, como uma prova de que fala, de fato, dialeto. É importante dizer que a interlocutora (entrevistadora) compartilha de parte do conhecimento linguístico, uma vez que é falante de italiano em sua variedade padrão, o que pode justificar certa liberdade por parte do casal para utilizar mudanças de código durante a entrevista em português. Os dialetos na Itália são variedades restritas ao âmbito familiar, muitas vezes, ligados apenas à modalidade oral, conforme declara Giuseppe:

- E pra escrever?

— Dialeto não escreve! [Em tom de indignação pela pergunta] [...] Você

9 De acordo com Grosjean (1982) e Gumperz (1982), a mudança de código envolve questões sociais que podem ser observadas conscientemente, a princípio, tornando-se gradativamente mais inconscientes, como é o caso da escolha do interlocutor e do papel social das línguas. 
na escola lá, não tem nada de dialeto. É tudo, a gramática é "tutta" aquela, ahn? Lá na escola não tem esse negócio de falar em dialeto e escrever em dialeto, "non c'è o dialeto, é o italiano próprio" [não tem o dialeto, é o italiano mesmo].

A aprendizagem do dialeto e do português foi, conforme podemos depreender dos relatos, dissociada do contexto escolar e diretamente relacionada à tradição oral. Embora Giuseppe e Giovanna falem o dialeto de Campobasso e a língua seja um dos aspectos ligados ao reconhecimento de uma identidade italiana, os entrevistados não têm pleno domínio de uso da língua nacional, ou seja, da variedade padrão de língua italiana. Ambos revelam esse desconhecimento linguístico em relação ao uso do italiano padrão:

— E o italiano que não é dialeto? (entrevistadora)

- É difícil. (Giovanna)

- Pra falar a gente tem um pouco de dificuldade, mas dá pra entender. $\mathrm{Na}$ televisão (a cabo) fica mais difícil entender as coisas, agora pra conversar, assim, dá pra entender melhor. (Giuseppe)

Podemos dizer que embora se considerem italianos, como veremos em suas autodefinições identitárias apresentadas a seguir, declaram que não falam e não escrevem italiano em sua variedade padrão, e possuem, também, dificuldade para sua compreensão. O bilinguismo, portanto, configura-se predominantemente pela presença de duas variedades: o dialeto italiano de Campobasso e a variedade do português, adquirida através do contato oral ${ }^{10} \mathrm{e}$ com frequentes marcas de empréstimos linguísticos. Assim, parece predominar uma identidade local italiana, denunciada pela declaração de que mantiveram o dialeto de Campobasso por quase 50 anos e

10 Grosjean (1985), Martin Jones e Romaine (1986) apregoam a necessidade de se abandonar a visão do bilíngue baseada na competência idealizada do monolíngue em favor de uma visão sociofuncional de bilinguismo. Nessa perspectiva, segundo Maher (1996), o sujeito bilíngue não é visto como produto da somatória de competências equivalentes às dos falantes monolíngues, visto que funciona em um universo discursivo próprio, particular, que prevê a utilização de mudanças de código e empréstimos linguísticos. 
pelo uso do português em uma variedade não padrão claramente marcado pelo sotaque italiano e por empréstimos linguísticos.

\section{Construção de identidades}

Sabendo do amplo debate que existe acerca do conceito de identidade ${ }^{11}$, consideramos útil uma breve exposição sobre a noção de identidade aqui adotada para refletir sobre os relatos dos imigrantes italianos. O conceito de identidade está intimamente ligado ao de sujeito pósmoderno, postulado por Hall, S. (1997, p. 10), ao discutir as consequências da modernidade e dos constantes deslocamentos da noção de sujeito ao longo dos debates na área da teoria social. O sujeito pós-moderno é visto como isento de identidade fixa: não tem uma identidade, mas muitas, presentes em situações diversas, que podem ser formadas por atributos até mesmo contraditórios entre si. Neste caso, percebemos que sentir-se italiano ou brasileiro depende das circunstâncias e dos interlocutores, pois, conforme o seu relato, o casal sente-se mais italiano no Brasil do que durante viagem à Itália.

Uma vez adotada essa definição de identidade para orientar nossa reflexão, descartam-se todos os outros critérios relacionados a uma visão purista, estável e fixa de identidade, tais como: critérios baseados no país onde nasceram, no tempo em que moram no Brasil, na língua que falam e na cultura que compartilham. O ponto de partida para a discussão sobre identidade foi uma pergunta que visava obter a opinião dos imigrantes entrevistados quanto às suas próprias identidades.

— Mas hoje o senhor é italiano ou brasileiro?

- Eu me considero italiano. (Giuseppe)

- A gente não é brasileiro. (Giovanna)

- A nossa documentação é tudo italiana. Aqui eu não voto, não faço nada. Quando tem eleição, eu não estou nem aí. (Giuseppe)

11 Sobre o tema, veja-se também Carriker, 1998. 
O reconhecimento de uma identidade italiana, neste caso, parece estar baseada em um critério burocrático, relativo à documentação no Brasil. Após essa resposta, a entrevistadora pergunta sobre a aspecto subjetivo:

— Tá bom, no papel vocês são italianos. E na cabeça, também?

- Opa! (Giuseppe)

- Ele é mais do que eu ainda, de manter a tradição de tudo, da comida (Giovanna)

- Eu não mudo minha nacionalidade não, eu gosto de italiano Eu, se eu como feijão mais do que um dia da semana, já não... (Giuseppe).

Nesse excerto, temos duas observações a serem feitas quanto aos enunciados de Giuseppe e Giovanna. A primeira é que o traço que parece caracterizar a italianidade refere-se à manutenção de práticas culturais relativas aos hábitos alimentares, pois Giovanna afirma que Giuseppe faz questão de "manter a tradição de tudo, da comida". A segunda observação é que através da fala de Giovanna, "ele é mais [italiano] do que eu", podemos perceber uma flexibilização do conceito de identidade italiana porque admite a possibilidade de existência de graus de italianidade.

Vê-se, portanto, que apesar de terem se autodefinido "italianos" quando estão no Brasil, no decorrer da entrevista a identidade apresenta certa flexibilidade, chegando inclusive a tornar-se ambígua. Ao contar sobre uma viagem que fizeram à Itália, em 1994, Giuseppe diz que os italianos não são acolhedores como os brasileiros e narra um episódio no qual foram mal recebidos:

Lá você pergunta alguma coisa, eles não te dão informação. Eu estava em Roma, eu com ela. Eu fui pedir informação do telefone que é pra ligar internacional. Ele fala "a me mi vien cercar informazione? Ma va..." (Giuseppe)

Giovanna narra, em seguida, outro episódio que despertou em ambos um sentimento de estrangeiridade na Itália por não conhecerem a prática de validar o bilhete de trem antes de embarcar: 
Outra coisa que eu não me conformei, sabe quando você compra a passagem do trem, depois você tem que passar naquela coisa, naquela maquininha na hora que você entra no trem. A gente não sabia, nunca tinha, ninguém falou nada, quando a gente chegou, já viu que a gente era estrangeiro. Por que é que não informa direito? Depois, quando a gente estava no trem, eles queriam cobrar multa porque não tinha passado o bilhete (Giovanna)

Giovanna declara-se estrangeira em sua terra natal e parece ser mais fácil reconhecer-se como italiana no Brasil do que na Itália. Provavelmente sentiram-se estrangeiros porque estavam em Roma e não tinham o domínio do italiano padrão e nem do dialeto romano. Entretanto, é provável que o funcionário da estação de trem os tenha reconhecido como italianos do sul, devido ao sotaque e uso do dialeto específico da região de onde provêm ${ }^{12}$, pois os italianos identificam-se através de seus dialetos e sotaques em relação à região de proveniência. No caso relatado, pode ter havido um contraste de imagens construídas, uma forte diferença entre o modo como Giuseppe e Giovanna construíram suas identidades na terra natal ("estrangeiros") e o modo como "o outro" (habitante de origem romana) os identificou quanto à identidade revelada.

Vimos, portanto, a mudança, durante a entrevista, de um autorreconhecimento de uma identidade italiana ao falarem de suas vidas no Brasil, seguida pela possibilidade de graus de italianidade ("Ele é mais [italiano] do que eu”), chegando, inclusive, à autodefinição de uma identidade estrangeira por ocasião de uma viagem à Itália.

Há ainda uma quarta possibilidade, caracterizada por momentos em que há o reconhecimento da convivência simultânea das identidades italiana e brasileira:

— Mas por que é que o senhor não volta a morar lá?

- (Giovanna intervém) Mas de jeito nenhum! (risos)

- É que nem eu digo, eu sou italiano e sou brasileiro ao mesmo tempo. A gente está aqui, já tem tudo implantado. Agora, eu vou pra Itália e eu não tenho mais nada lá.

- Mas se o senhor vender aqui, o senhor faz a vida lá. (entrevistadora)

12 Penna (1998) aponta que a especificidade da representação de identidade encontra-se no vínculo com a problemática social e afirma que as duas direções do jogo de reconhecimento - autorreconhecimento e a alter-atribuição de identidades - articulam-se dinamicamente e nem sempre são coincidentes. 
- Mas, eu vou pra lá enfrentar o frio. Se você fala pra mim, eu te dou uma passagem de graça pra Itália pra enfrentar o frio, eu não vou. Você vê, a gente já se acostumou com o clima daqui.

Em meio à fala, Giuseppe se dá conta da aparente contradição na definição de sua própria identidade:

- Agora eu eu sou brasileiro já, olha agora eu já mudei pra brasileiro.

- Ele não é nenhum patriota de lá não (Giovanna).

- Eu sou italiano, tudo bem, eu gosto, mas o frio, eu já prefiro o calor.

Não seria possível compreender a afirmação de Giuseppe à luz da noção de identidades individuais como sendo puras, íntegras e imutáveis ${ }^{13}$. O que se observa aqui é um sujeito fragmentado, como afirma Hall, S. (1997), composto não de uma, mas de várias identidades, algumas vezes contraditórias ou não resolvidas, e que mudam em diferentes momentos, como neste caso, em que predomina ora uma (italiana), ora outra (brasileira) ${ }^{14}$.

Os traços claros que os aproximam da identidade italiana são o uso do dialeto e os hábitos alimentares mantidos, e são traços caracterizantes de uma identidade brasileira a afinidade com o povo (mais cordial) e com o clima, e as raízes criadas aqui. A imagem da Itália como um local no qual não mantêm raízes (Giuseppe afirma: "não tenho mais nada lá") aparece em oposição à imagem do Brasil, que representa, acima de tudo, um país em que conquistaram boas condições econômicas: "tudo o que a gente conseguiu foi aqui. Lá na Itália, a gente só passou fome, necessidade".

Considerando-se a derrota dos países do eixo (Alemanha, Itália e Japão) na II Guerra mundial em 1945, a Itália atravessava sérios problemas econômicos. Embora o contexto socioeconômico italiano dos anos 50 tenha sido completamente diferente daquele encontrado no final do século XIX e início do século XX, o discurso que justifica a decisão de imigrar para o Brasil é o mesmo, ou seja, "escapar da fome e da miséria", conforme revelou Giovanna.

$\mathrm{O}$ quadro de dificuldades econômicas em que se encontravam representava um terreno fértil

13 Rajagopalan (1998, p. 26) diz que a visão purista de identidade foi tomada como acrítica pela linguística desde sua estreia, que tomou essa questão como pacífica. Aponta ainda "a necessidade de começarmos a levar seriamente em conta a possibilidade de identidades proteiformes, em permanente estado de fluxo" (p. 42).

14 Hall, S. (1997, p. 10) afirma, a partir de um conceito pós-moderno de indivíduo, que "o sujeito assume identidades diferentes em momentos diversos, identidades que não estão unificadas em torno de um self coerente. Dentro de nós coexistem identidades contraditórias, pressionando em direções diversas, de modo que nossas identificações estão sendo continuamente mudadas". 
para propagandas enganosas que atraíam os italianos para o Brasil. Giuseppe, por exemplo, pensava ter adquirido um pedaço de terra vendido por um agente brasileiro na Itália:

- Saíram 9 famílias, 58 pessoas da minha cidade. Cada uma pagou lá, antes de sair, "trecentomila lire" por um terreno aqui no Brasil. (Giuseppe)

(Giovanna interrompe)

- Roubaram eles, não tinha terreno nenhum.

A história dos imigrantes que vinham ao Brasil para escapar da miséria em que se encontrava o país e as diferenças culturais (hábitos alimentares e higiênicos) deram origem ao preconceito e a uma imagem negativa do italiano. Outro aspecto causador do preconceito expresso em relação aos italianos é, conforme aponta Gabriel (1995, p. 169), a competitividade que os italianos representavam ao mercado de trabalho paulista. A sociedade paulista, apesar de depender da mão de obra italiana para a produção do café, não havia se preparado para competir com esses estrangeiros pelo mercado de trabalho urbano. Aos olhos dos nacionais, os italianos eram substitutos da mão de obra escrava e vinham para permanecer no campo, mas a maior parte dos italianos não permaneceu no campo. Essa imagem de italianos, consolidada durante o período de imigração de massa, permanece presente na sociedade que, como forma de protestar contra a competitividade pelo trabalho urbano, se expressa através de ações preconceituosas.

A fala de Giuseppe, referente ao período em que já moravam na zona urbana de Rio Claro, aponta certa hostilidade dos brasileiros em relação aos italianos que representavam socialmente uma ameaça ao mercado competitivo de trabalho: "eles olhavam pra gente como se falassem 'por que você veio aqui roubar o meu pão?'”.

$\mathrm{O}$ relato de Giovanna complementa o de Giuseppe, à medida que denuncia o preconceito dos brasileiros através de estigmas criados em relação aos italianos: "italiano era mal visto, eles falavam 'italiano polenteiro', italiano era tudo polenteiro. E a gente, do sul da Itália, nem tem esse hábito, né?”.

A palavra "polenteiro" é uma alusão à polenta, prato típico da região do Vêneto. É interessante lembrar que até 1898 a região era responsável pela maior parte da imigração italiana para o Brasil, e mesmo que posteriormente as regiões sul tenham passado a enviar maior número de 
imigrantes que o norte (GABRIEL, 1995), já havia se consolidado uma imagem estigmatizada ${ }^{15}$ do italiano com base nos primeiros fluxos predominantemente vênetos.

Não se poder esquecer, além disso, um fator histórico relacionado especificamente ao período da II Guerra, que, possivelmente, contribuiu para reforçar a imagem negativa dos italianos no Brasil, ou seja, a participação do Brasil na II guerra contra os países do eixo, Alemanha, Itália e Japão ${ }^{16}$, a partir de 1942. Após a II Guerra, a imagem dos italianos no Brasil não era favorável, uma vez que o Brasil havia lutado contra os italianos na Itália e, apesar de ter colaborado para a vitória dos países aliados, saiu com um saldo de 451 oficiais e praças mortos na Itália durante as batalhas de Camaiore, Monte Castelo, Castelnuovo, Montese e Fornovo (ENCICLOPÉDIA ENCARTA, 2000).

Os imigrantes italianos encontraram péssimas condições físicas quando chegaram às fazendas de café, agravadas pelas barreiras linguísticas ${ }^{17}$ que dificultavam a inserção destes na sociedade local. As falas apresentadas neste trabalho denotam o trabalho excessivo a que os entrevistados foram submetidos e as precárias condições de instalação que encontraram ao chegar ao Brasil, a uma fazenda produtora de café, na cidade de Cornélio Procópio, no estado do Paraná. As condições oferecidas e o ritmo de trabalho exigido pelos fazendeiros chegam a se aproximar ao regime escravagista anteriormente vigente, conforme este depoimento de Giuseppe: "nós sofremos, nós fomos até vendidos! Chegou um fazendeiro, aquele que pagou mais, levou".

Atualmente, a imagem dos italianos no Brasil é, em geral, positiva, bem diferente daquela descrita pelos imigrantes que chegaram no final do século XIX e meados do século XX.

É possível dizer que houve uma reconstrução da imagem do italiano na sociedade brasileira e no mundo e, consequentemente, uma autorreconstrução das identidades dos imigrantes italianos no Brasil, quando passaram a ser vistos de outra forma. A identidade do italiano no final do século XX foi modificada por circunstâncias histórico-sociais e os estigmas ligados à nação foram apagados, como, por exemplo, os de "polenteiro", "pobre".

15 Goffman (1968, p. 13) define "estigma" como "um atributo que é fortemente desonroso e apresenta a classificação de três tipos de estigmas: a) ligados a deformidades do corpo, b) estigmas ligados ao caráter individual e c) estigmas ligados a raça, nação e religião".

16 No dia 22 de agosto de 1942, Getúlio Vargas anunciou o rompimento das relações diplomáticas e comerciais do Brasil com os países do eixo. Antes mesmo dessa data, G. Vargas já havia estabelecido leis que visavam à nacionalização do ensino no Brasil. Os decretos relativos a essa campanha de nacionalização são de 1938, 1939 (2 decretos), 1940 e 1941 (KREUTZ, 1991) e consistiam, entre outras coisas, da proibição do uso de qualquer material didático que não fosse em língua portuguesa, proibição da atuação de professores e diretores de escola que fossem estrangeiros, proibições de importações e impressões de livros-texto de língua estrangeira etc.

17 Os problemas relativos às barreiras linguísticas serão tratados na parte do texto dedicada a identidades. 


\section{Considerações finais: contribuições deste estudo para reflexões sobre os conceitos de identidade, bilinguismo e minorias linguísticas}

O estudo das narrativas de um casal de imigrantes italianos permitiu o levantamento de questões relativas ao fenômeno de bilinguismo e ao processo de construção de identidades de imigrantes. O ponto de partida foi uma breve reconstrução histórica do cenário imigratório a partir do qual italianos e descendentes de italianos construíram e (re)constroem suas identidades.

Abandonando a visão do sujeito bilíngue como uma somatória de competências equivalentes às dos falantes monolíngues em favor de uma visão do bilíngue como detentor de um universo discursivo próprio, apontamos a presença de um tipo de bilinguismo caracterizado pela utilização do dialeto de Campobasso e de uma variedade não padrão do português com frequentes mudanças de código, aprendidas através do contato oral e determinadas por uma situação diglóssica. Os contextos de uso são claramente definidos, ou seja, no âmbito familiar falam o dialeto e nos contatos sociais no Brasil, o português, em uma variedade que apresenta mudanças de código e empréstimos linguísticos do dialeto italiano, revelando, portanto, um universo discursivo próprio ligado à identidade italiana ${ }^{18}$.

Para refletir sobre a construção de identidades no contexto desta família de imigrantes italianos, adotamos o conceito proposto por Hall, S. (1997), segundo o qual não há uma identidade fixa, permanente ou essencial. Ao tratar do conceito de sujeito pós-moderno, o autor aponta a existência de várias identidades que o compõem, e afirma que:

A identidade tornou-se uma festa móvel: formada e transformada continuamente em relação às maneiras pelas quais somos representados ou tratados nos sistemas culturais que nos circundam. Ela é histórica, não biologicamente definida. O sujeito assume identidades diferentes em momentos diversos, identidades que não estão unificadas em torno de um self coerente. Dentro de nós coexistem identidades contraditórias, pressionando em direções diversas de modo que nossas identificações estão sendo continuamente mudadas. (HALL, S. 1997, p. 10).

18 Maher (1996), em estudo sobre identidades de professores índios, aponta a presença da fala de uma variedade indianizada do português, que neste caso não é uma língua meramente emprestada do branco, já que muitos índios dela se apropriam e a moldam, a fim de construir e marcar suas identidades. 
Vimos, com base na análise das narrativas, que a identidade se desenvolve diferentemente em diversos momentos. Inicialmente, há o reconhecimento de uma identidade italiana quando relatam sobre a vida no Brasil (i) e de graus de italianidade (ii), mas quando se encontram em sua terra natal sentem-se estrangeiros (iii), e em um dado momento da entrevista declaram a pertinência às duas identidades, brasileira e italiana, simultaneamente (iv).

Os traços através dos quais parecem revelar sua italianidade são: a manutenção do uso do dialeto de Campobasso, o uso de uma variedade do português claramente marcada por empréstimos linguísticos da língua materna e a manutenção de práticas culturais ligadas aos hábitos alimentares. A brasilidade é revelada através da declaração de maior identificação com o clima e com o povo brasileiro (que consideram mais cordial), e também pela história das raízes que já criaram aqui ("Eu não tenho mais nada lá”, afirma Giuseppe). As duas identidades convivem com o predomínio de uma ou outra (brasileira ou italiana) em diferentes momentos. A identidade apresenta-se, pois, proteiforme (RAJAGOPALAN, 1998).

Observamos, através de um percurso histórico da imagem do italiano no Brasil, que até mesmo os atributos estigmatizados (GOFFMAN, 1968), como "pobre", "polenteiro", foram modificados historicamente, o que reforça a ideia de que as identidades são um construto sóciohistórico por natureza e por isso, essencialmente político, ideológico e em constante mutação (MAHER, 1996).

A presença de núcleos familiares isolados de imigrantes, em geral, não é lembrada em trabalhos sobre minorias linguísticas no Brasil. Como este núcleo familiar, existem muitos outros "invisíveis" na literatura que revelam conflitos de identidades e manutenção de um tipo de bilinguismo dissociado da variedade padrão do país de origem e da variedade padrão do português. Este tipo de trabalho pode trazer contribuições para estudos sobre construções de identidades bilíngues e aponta a necessidade de dedicar espaço para reflexões sobre núcleos familiares de imigrantes como parte dos estudos de minorias linguísticas, em que parecem prevalecer estudos sobre contextos de grupos organizados e facilmente identificados como comunidades. 


\section{Referências}

BARRETO, S. Italianos do Brás - Imagens e Memórias. São Paulo: Brasiliense, 1994.

BERTONHA, J. F. Sob o signo do Fascio: O fascismo, os imigrantes italianos e o Brasil, 1922-1943. 1998. 423 f. Tese (Doutorado em História Social). Campinas: IFCH, Unicamp, 1998.

CARRIKER, M. K. (Re)construção de Identidades em Narrativas na Primeira Pessoa: Casos de Bilíngües. 1998. 173 f. Dissertação (Mestrado em Linguística Aplicada). Campinas: IEL, Unicamp, 1998.

CASTRO, G. M. Pedrinhas Paulista: Memória e Invenção. 2002. 147 f. Tese (Doutorado em Geografia Humana). São Paulo: FFLCH, USP, 2002.

CAVALCANTI, M. C. Estudos sobre Educação Bilíngüe e Escolarização em Contextos de Minorias Linguísticas no Brasil. In Revista D.E.L.T.A., v. 15, n. Especial: 385-417, 1999.

DI GIANNI, T. P. Italianos em Franca, Franca: UNESP, 1997.

FACCHINETTI, L. A imigração italiana no segundo pós-guerra e a indústria brasileira nos anos 50. 2003. 139 f. Dissertação (Mestrado em História Social). Campinas: IFCH, Unicamp, 2003.

GABRIEL, M. C. C. Além das fronteiras do colonato ( $O$ ajustamento da coletividade italiana à sociedade local campineira durante a imigração - 1886-1920). 1995. Dissertação (Mestrado em História Social). Campinas: IFCH, Unicamp, 1995.

GOFFMAN, E. Stigma: notes on the management of spoiled identity. Londres: Penguin, 1968.

GROSJEAN, F. Life with two languages: an introduction to bilingualism. Cambridge MA: Harvard University Press, 1982.

GUMPERZ, J.J. Discourse Strategies. Cambridge: Cambridge University Press, 1982.

HALL, M. M. Italianos em São Paulo (1880-1920). In Anais do Museu Paulista, XXIX, 1979. . Imigrantes na cidade de São Paulo. In PORTA, P. (org.) História da cidade de São Paulo. São

Paulo: Paz e Terra, v. 3, 2004, pp. 121-151.

HALL, S. Identidade Cultural. São Paulo: Fundação Memorial da América Latina, 1997.

KREUTZ, L. O Professor Paroquial. Porto Alegre: Universidade do Rio Grande do Sul, 1991.

MAHER, T. J. M. Ser Professor sendo índio: Questões de lingua(gem) e identidade. $261 \mathrm{f}$. Tese (Doutorado em Linguística Aplicada). Campinas: IEL, Unicamp, 1996.

MARTIN-JONES, M.; ROMAINE, S. Semilingualism: a half-baked theory of communicative competence. In Applied Linguistics, v.7, n.1: 26-38, 1986.

MENEZES, M. A. Histórias de Migrantes. São Paulo: Loyola, 1992.

MICROSOFT CORPORATION. Enciclopédia Encarta 2.000. Ano 2000. (tipo de suporte CD-ROM). 
PENNA, M. Relatos de Migrantes: questionando as noções de perda de identidade e desenraizamento. In SIGNORINI, I. (org.). Linguagem e Identidade: elementos para discussão. Campinas: Mercado das Letras, 1998, pp. 89-112.

RAJAGOPALAN, K. O conceito de identidades em Linguística: é chegada a hora para uma reconsideração radical?. In SIGNORINI, I. (org.). Linguagem e Identidade: elementos para discussão. Campinas: Mercado das Letras, 1998, pp. 21-45.

ROMAINE, S. Bilingualism. Oxford: Blackwell, 1995.

SAVILLE-TROIKE, M. The Ethnography of Communication. Oxford: Blackwell, 1989.

SKUTNABB-KANGAS, T. Bilingualism or not: The Education of Minorities. Bristol, Multilingual Matters, 1981.

TRENTO, A. Là, dov'è la raccolta del caffè - L'immigrazione Italiana in Brasile (1875-1940). Padova: Pubblicazione della Facoltà di Lettere e Filosofia, 1984.

Do Outro Lado do Atlântico: Um Século de Imigração Italiana no Brasil. São Paulo: Nobel, 1989.

TRUDGILL, P. Introducing language and society. London: Penguin, 1992. 